\title{
A Documentação na Petrobrás
}

Affonso Celso M. de Paula Licenciado em Letras Clássicas Bibliotecário. Chefe do Setor de Documentaçấo Técnica e Patentes do Centro de Pesquisas e Desenvolvimento - PETROBRÁS

\section{INTRODUÇÃO}

A

indústria do petróleo se caracteriza pelo seu dinamismo e permanente transformação, como um dos setores de vanguarda no atual mundo tecnológico. Propelem-na três fôrças principais:

a) a importância estratégica do petróleo e seus derivados;

b) lucros compensadores para os investimentos, sobretudo na refinação e distribuição;

c) o elevado grau de competição entre as emprêsas petroleiras.

Nosso País, pela Lei 2.004 , de $3 / 10 / 1953$, optou pelo monopólio estatal dessa atividade vital para sua segurança e seu desenvolvimento, instituindo a Petróleo Brasileiro - S. A. PETROBRÁS, como instrumento de execução.

Para a implantação da indústria de petróleo brasileiro foram de grande utilidade o acervo em experiência, bens materiais e realizações legadas pelo Conselho Nacional do Petróleo. Contudo, a imediata expansão e diversificação de atividades, como requisito latente e implícito na Lei 2.004, impôs antes de tudo um revigoramento dos programas de formação e aperfeiçoamento de pessoal, de modo que, ao longo do tempo, em substituição à mão-de-obra estrangeira, pudesse a indústria do petróleo suprir-se, no próprio País, dos quadros de pessoal suficientemente adestrado para acionar, com eficiência, técnica e equipamentos complexos.

Esta tarefa, no primeiro esquema de organização da PETROBRÁS, foi confiada ao Centro de Aperfeiçoamento e Pesquisas de Petróleo (CENAP), incumbido ao mesmo tempo de realizar pesquisas tecnológicas e desenvolver atividades de documentação. 


\section{CONSUMO E PRODUÇÃO DA INFORMAÇÃO}

As metas do programa de aperfeiçoamento de pessoal vêm sendo paulatinamente alcançadas. Dispõe a PETROBRÁS de técnicos de nivel superior na quantidade e na qualidade requeridas pelos seus planos de expansão. Continuam em funcionamento os cursos de pós-graduação em que se especializam êstes técnicos. Um verdadeiro sistema de capacitação de mão-de-obra, representado por um órgão central coordenador e orientador das agências de execução, vem firmando conceito na Emprêsa, mercê dos bons resultados que oferece.

Bem analisando e interpretando os fatos, constata-se que o esforço de aperfeiçoamento de pessoal nada mais foi que um conjunto de medidas capazes de assegurar a rápida absorção e assimilação de conhecimentos especializados, corporificados numa tecnologia produzida fora do País. O fluxo das informações foi, como não poderia ter sido de outra forma, predominantemente, no sentido de fora para dentro.

E no momento interessante constatar como, graças a êste capital tecnológico adquirido inicialmente, o seu investimento, nas diversas frentes de trabalho, tem gerado, por seu turno, adaptações, e improvisações e, em menor escala, inovações no sentido técnicocientifico, o que corresponde, a partir daquela semente lançada no solo fecundo de uma ampla e diversificada experimentação operacional, ao surgimento de uma tecnologia própria, adequada aos nossos problemas e necessidades. Justifica-se plenamente, portanto, a atenção e o cuidado que a Emprêsa vem dedicando ao aspecto da pesquisa tecnológica. $\mathrm{Na}$ nova estrutura da Emprêsa, amplas perspectivas abrem-se ao Centro de Pesquisas e Desenvolvimento (CENPES) que, quando dotado das instalações e equipamentos, agora em fase de avaliação e dimensionamento, poderá desdobrar em consideráveis proporções o trabalho pioneiro empreendido pelo extinto CENAP. Sua instituição tem, pois, o sentido inequivoco de, por ora, aglutinar e catalisar as aptidões e possibilidades de pesquisa tecnológica para, a prazo médio, convertê-las em empreendimentos definidos $e$, até certo ponto, autônomos no quadro de atividades da PETROBRÁS. Será êste o momento em que a Emprêsa deixará de ser apenas consumidora, passando então à condição simultânea de produtora de informação especializada, de cunho original.

\section{OS PRIMORDIOS DA DOCUMENTAÇAO NA PETROBRÃS}

Pela definiçăo de suas atribuiçõ̃es bem como pelo seu engaste na estrutura do extinto Centro de Aperfeiçoamento e Pesquisas de Petróleo, onde preponderavam as atividades de treinamento, o Setor 
de Intercâmbio e Documentação foi fortemente marcado como apoio direto e imediats aos programas de aperfeiçoamento.

Eis suas atribuições originais:

a) manter fermanente contato com os centros universitários e industriais do País e do estrangeiro que possuem programas ou atividades de formação e aperfeiçoamento de pessoal para a indústria de petróleo, a fim de conhecer os métodos de ensino que adotam e outros processos de interêsse do CENAP;

b) manter atualizada a bibliografia de interêsse da PETROBRÁS, oferecendo às bibliotecas das Unidades as indicações bibliográficas de literatura especializada no interêsse da indústria de petróleo;

c) manter permanente intercâmbio com os estabelecimentos de ensino do Pais com o propósito de oferecer aos corpos docente e discente informações no interêsse do ensino sôbre as atividades da PETROBRÁS, suas necessidades de pessoal qualificado e os conhecimentos que devem possuir os que pretendam candidatar-se a emprêgo na PETROBRÃS;

d) organizar a documentação das atividades da PETROBRAS que interesse ao ensino e treinamento dos diferentes técnicos e especialistas para a indústria do petróleo, reunindo informações sôbre ocupações, funções e tarefas desempanhadas nas diferentes Unidades da PETROBRÁS;

e) manter, atualizado, material didático e os programas de ensino e de estágios em uso na Emprêsa e que permitam atender às atividades de formação e de aperfeiçoamento de pessoal;

f) publicar um boletim técnico.

Podem ser reunidas em dois grupos as atividades que marcam o início do funcionamento do referido Setor. De um lado, aquelas de proveito imediato para o treinamento: coleta e organização do material didático em uso nos cursos de diferentes niveis, mantidos pela Emprêsa; intercâmbio com instituições especializadas, do País e do exterior, para obtenção de informações de interêsse para as atividades de aperfeiçoamento; estudos e pesquisas ligados aos problemas do treinamento; preparo e edição de material de divulgação e informação profissional. De outro lado, sobressaiam as atividades que, encetadas com oportunidade e adequação, acabariam caracterizando o Setor como órgão coordenador e orientador da função documentária na Emprêsa, se bem que ao preço de um desenvolvimento menos satisfatório das tarefas mencionadas no parágrafo anterior. $\mathrm{O}$ primeiro passo foi o levantamento, com a colaboração do Instituto Brasileiro de Bibliografia e Documentação, dos recursos Bibliográficos com que, à época, a PETROBRÁS contava, do que resultaram os Catálogos Coletivos de Livros, Folhetos e Filmes e de Periódicos, ambos editados também com concurso do 
I.B.B.D. Ao mesmo tempo se iniciou a compilação da Bibliografia Brasileira de Petróleo que, em sua primeira etapa (agora em publicação), arrola a literatura sôbre a matéria editada no País, desde a $2^{\text {a }}$ metade do século passado até 1958 . Os Resumos Indicativos começaram a ser editados em 1957, apresentando matéria selecionada sôbre refinação de petróleo, condensada pelos técnicos do então Setor de Pesquisas do CENAP. Paulatinamente êstes Resumos se ampliaram e se aperfeiçoaram, conforme teremos oportunidade de relatar adiante. Ainda no campo da bibliografia, começou o Setor a compilar levantamentos de literatura sôbre aspectos específicos, em atendimento a requisições de técnicos dos mais diversos Setores da Emprêsa.

É digno de nota o esfôrço que o CENAP sempre desenvolveu e ùltimamente vem sendo intensificado pelo CENPES, no sentido de fomentar a instalação de bibliotecas nas Unidades de operação da Emprêsa, espalhadas por todo o País. Coerente com essa politica de organizar e manter coleções especializadas junto aos núcleos de maior expressão, instalou o CENAP três bibliotecas, sob sua responsabilidade direta: a Biblioteca Central assim chamada pelo fato de servir aos técnicos da Administração Central da PETROBRÁS; a Biblioteca do Curso de Refinação (que servia também aos técnicos do Setor de Pesquisas, embrião do futuro CENPES) e a Biblioteca dos Cursos do CENAP na Bahia.

Fruto dêsse incentivo e dêsse exemplo foi a criação de bibliotecas nas grandes Unidades de operação da Emprêsa, como a Região de Exploração do Norte, Região de Produção da Bahia, Terminal de Madre de Deus, Refinarias Landulpho Alves, Duque de Caxias e Presidente Bernardes, Conjunto Petroquimico Presidente Vargas e Obra de Construção da Refinaria Alberto Pasqualini. É, portanto, um conjunto de 11 bibliotecas que, mais a do Serviço Jurídico, e os recém-criados Setores de Documentação do Serviço de Pessoal e do Serviço de Organização e Gerência Administrativa, compõem, sob a assistência e orientação do Setor de Documentação Técnica e Patentes, o incipiente sistema documentário da PETROBRÁS.

Como fecho dêste breve retrospecto, mencionamos a atividade editorial empreendida pelo CENAP desde os primórdios de sua atuação. O preparo e lançamento do Boletim Técnico da PETROBRÁS constituiu o primeiro passo no sentido de um empreendimento sistemático e orgânico de publicações técnicas com as quais, registrando-se e difundindo se a experiência e os conhecimentos de nossos técnicos, se procura contribuir para acelerar a formação de um "know-how" próprio.

\section{NOVAS DIMENSOES}

A recente transformação de estrutura organizacional por que passou a PETROBRÁS possibilitou a constituição do Centro de 
Pesquisas e Desenvolvimento, que incorporou as atividades de pesquisas e de documentação até então conduzidas pelo CENAP, separando-as em definitivo do treinamento, com perspectivas promissoras de um desenvolvimento rápido, mercê de condições institucionais mais apropriadas. Os encargos de aperfeiçoamento de pessoal e a parcela das atividades documentárias a êle diretamente vinculadas passaram a constituir a nova Divisão de Treinamento do Serviço de Pessoal da PETROBRÁS.

O antigo Setor de Intercâmbio e Documentação, agora transformado no Setor de Documentação Técnica e Patentes, passou a ter as seguintes atribuições:

a) desenvolver, no campo de documentação e no âmbito da Emprêsa, serviços técnicos que ensejem o máximo aproveitamento ta informação do interêsse da indústria do petróleo;

b) planejar, coordenar e acompanhar tècnicamente os serviços documentários na Emprêsa, dando-lhes orientação e assistência;

c) reunir e organizar documentos relacionados com a indústria do petróleo e executar os serviços necessários para a sua melhor utilização, dispondo, como instrumento de trabalho e de referência, de uma biblioteca de tecnologia e ciência, onde procederá às experimentações dos métodos de contrôle documentário;

d) controlar a informação técnica que possa contribuir para o desenvolvimento da indústria do petróleo e que se destine à divulgação, elaborando os instrumentos que facilitem, ao máximo, a sua acessibilidade e aproveitamento;

e) acompanhar a evolução da legislação sôbre patentes, sugerindo as modificações de interêsse da Emprêsa;

f) proceder, quando solicitado, a levantamentos completos das patentes existentes e relacionadas com assuntos específicos da indústria do petróleo e do xisto;

g) acompanhar os progressos da tecnologia da indústria de petróleo, refletidos nos pedidos e nas patentes de invenção;

h) assessorar os órgãos da Emprêsa nos assuntos relacionados com patentes;

i) organizar o arquivo das patentes concedidas pelo Departamento Nacional da Propriedade Industrial e relacionadas com a indústria de petróleo e de xisto;

j) consolidar as informações prestadas pelos demais setores do CENPES e órgãos da Emprêsa consultados e emitir parecer técnico sôbre os pedidos de privilégios e patentes em causa;

l) produzir documentos, gráficos e audiovisuais, de caráter periódico ou monográfico, que registrem pesquisas, experiência e estudos e constituam fontes de referência técnico-científica.

Ressalte-se que os encargos relativos a patentes foram transitòriamente atribuidos ao Setor, mas a prazo médio se prevê a sua 
desvinculação, para eventual constituição de um setor especifico, dentro do próprio CENPES.

Configurada sua condição de órgão central de documentação na Emprêsa, para o bom desempenho de suas atribuições, o Setor de Documentação Técnica e Patentes reuniu suas funções em quatro grupos principais, a saber:

- planejamento e desenvolvimento do sistema documentário;

- organização e administração da documentação;

- contrôle da informação e traduções;

- produção de documentos.

\section{1 - PLANEJAMENTO E DESENVOLVIMENTO DO SISTEMA DOCUMENTÁRIO}

A existência de pessoal destinado exclusivamente a esta tarefa se justifica não só pelo porte dos serviços documentários da PETROBRÁS e volume de seus encargos (12 bibliotecas e 2 setores de documentação), como também pela necessidade de se manter constante entrosamento entre êstes serviços e fazê-los convergir para os objetivos gerais prefixados.

Compete-lhe o planejamento de novos serviços, a coordenação e o acompanhamento dos já existentes, a padronização e racionalização de rotinas, o estudo e equacionamento dos problemas ligados ao desempenho da rêde documentária.

Além do planejamento das instalações físicas de várias bibliotecas da Emprêsa, contam-se como realizações mais expressivas neste campo a elaboração de normas reguladoras do empréstimo e de outros serviços prestados pelas bibliotecas; a fixação de modelos padronizados de relatório e de boletim de biblioteca; a orientação para o tratamento e recuperação de informações contidas em catálogos industriais etc.

Recentemente foram concluídos dois estudos do maior interêsse para a atualização e ampliação dos serviços documentários da Emprêsa. O primeiro dêles para avaliar a conveniência e adequação de introduzir processos mecânicos no armazenamento e recuperação de informações, e o segundo, para instalar sistemas de processamento da informação técnica produzida internamente. Dois outros estudos, não menos importantes, acham-se em pauta: sôbre a posição das bibliotecas na estrutura dos órgãos a que servem, e sôbre a atual estrutura do sistema documentário e dos respectivos proietos de expansão, êste último em regime de convênio com o I.B.B.D. .

O objetivo comum de tôdas as iniciativas, realizadas e programadas, no serviço de planejamento e desenvolvimento, tem sido 0 de assegurar o crescimento harmônico e racional dos serviços documentários da Emprêsa, em crescente integração na busca dos 
objetivos comuns, quadro em que se inseriu com real oportunidade - I Seminário de Documentação da PETROBRÁS, realizado em agôsto p.p., ocasião em que foram apresentados e discutidos cinco temas, em meio a vivo interêsse por parte dos trinta bibliotecários da Emprêsa.

\section{2 - ORGANIZAÇÃO E ADMINISTRAÇÃO DA DOCUMENTAÇÃo}

É, por definição, o segmento do órgão central de documentação incumbido de recolher e organizar a literatura de interêsse da Emprêsa, submetendo-a aus processos técnicos iniciais para ulterior utilização.

Quando plenamente desenvolvido, deverá compreender a compra, permuta e doação de material bibliográfico centralizadas, serviços já planejados em pormenores, mas ainda não efetivados por dificuldades de ordem interna.

As atividades já em andamento abrangem o tratamento técnico dos documentos, a manutenção e atualização dos Catálogos Coletivos da Emprêsa.

O tratamento técnico dos documentos vem sendo executado em bases cooperativas; uma biblioteca, ao adquirir um livro, dá ciência ao Setor, que então informa se a peça já está ou não representada no Catálogo Coletivo. Em caso positivo, automàticamente é enviada à Biblioteca coleção completa das fichas catalográficas referentes ao livro adquirido; em caso negativo, a Biblioteca, uma vez informada, efetua a catalogação e classificação do livro, enviando a ficha principal ao Setor para normalização e posterior duplicação.

Em ambos os casos as fichas são reproduzidas automàticamente, com o emprêgo de uma máquina Flexowriter da Friden.

Os Catálogos Coletivos já tiveram uma primeira edição cobrindo o material existente na Emprêsa até 1958. Desde então o Catálogo Coletivo de Livros, Folhetos e Filmes vem sendo atualizado em forma de fichas, tendo sido lançada em 1965 uma segunda edição do de Periódicos. Convém mencionar que se acham em andamento as providências para mecanizar o de Livros, com auxílio do sistema de processamento de dados IBM 1.401 disponível na Emprêsa. Quando inteiramente transposto para memória magnética - e esta etapa inicial é a mais árdua - o Catálogo poderá ser fàcilmente mantido atualizado e, o mais importante, reeditado de tempos em tempos com o minimo dispêndio de trabalho.

\section{3 - CONTRÔLE DA INFORMAÇÃO E TRADUÇÕES}

Consta essencialmente do preparo e divulgação de bibliografias especializadas: os Resumos Indicativos da Indústria do Petróleo, a Bibliografia Brasileira de Petróleo, além das bibliografias avulsas. 
Os Resumos Indicativos da Indústria do Petróleo constituem uma bibliografia corrente que difunde literatura estrangeira e nacional (esta, sistemàticamente), selecionada sobretudo em periódicos especializados integrantes do acervo da Emprêsa. Como tantas outras, é também uma iniciativa empreendida com a participação do conjunto de bibliotecas da Emprêsa, sob a direção do Setor de Documentação Técnica e Patentes, que recolhe, normaliza e faz publicar resumos elaborados pelos técnicos.

A Bibliografia Brasileira de Petróleo apresenta, em sua $1^{\text {a }}$ etapa de compilação, referências que vão desde 1864 até a primeira metade de 1958.

Esta parte se acha em publicação e o propósito do Setor é manter a Bibliografia atualizada, lançando edições periódicas.

O serviço de bibliografias avulsas é mantido para atender às necessidades mais prementes dos técnicos da Emprêsa em seus estudos, pesquisas e trabalhos práticos. Por sua iniciativa, o Setor de Documentação Técnica e Patentes tem compilado algumas bibliografias para se antecipar às necessidades dos órgãos da Emprêsa no tócante ao acervo básico que devem adquirir a fim de aparelhar as bibliotecas especializadas que instalam.

No campo das traduções, o Setor, a pedido de técnicos, tem feito realizar algumas; o objetivo imediato, no entanto, é coordenar e racionalizar, na medida do possivel, a fôrça de trabalho representada pelos tradutores da Emprêsa, além de cadastrar o pessoal, interno e externo, em condições de executar traduções especializadas.

\section{4 - PRODUÇÃO DE DOCUMENTOS}

É um serviço do Setor que tem alcançado significativos progressos. A edição de material técnico começou, conforme já nos referimos, com o Boletim Técnico da PETROBRÁS, destinado a ser o repositório das experiências e progressos dos especialistas brasileiros na tecnologia do petróleo. Desde cedo, porém, se percebeu que também se fazia mister o registro dessas experiências e progressos com mais profundidade, dai resultando a instituição da publicação seriada "Ciência-Técnica-Petróleo", na qual já foram editadas, até aqui, 10 monografias, num esfôrço apreciável para sedimentar e difundir a incipiente tecnologia brasileira de petróleo.

Ambas as publicações atribuem prêmios, variáveis de Cr $\$ 50$ mil a Cr $\$ 300$ mil, aos autores dos trabalhos editados. Cogita-se agora de promover a venda de publicações, seja para amortizar os custos de impressão, seja para ampliar a frente de distribuição externa; prevê-se também a melhoria dos prêmios atuais, num con- 
junto de medidas tendentes a converter a atividade editorial do Setor em empreendimento efetivamente dinâmico e atuante.

$\mathrm{Na}$ reprodução de documentos, atende-se sobretudo a pedidos decorrentes da consulta aos Resumos Indicativos. Por deficiência da aparelhagem disponivel, recorre-se a serviços de fora da Emprêsa quando o texto a reproduzir se acha encadernado. Estamos utilizando a cooperação da Biblioteca do Congresso norte-americano para adquirir cópias de textos técnicos não existentes no País. Eventualmente, temos recorrido a outras instituições congêneres, nacionais e estrangeiras.

\section{5 - OS COMPONENTES DO SISTEMA DOCUMENTÁRIO}

É de justiça realçar o útil trabalho que vem sendo desenvolvido pelas bibliotecas da Emprêsa, postadas que se acham na linha de frente da «batalha da informação». Localizadas sobretudo junto às Unidades de operação da Emprêsa, prestam os mais úteis serviços de referência e empréstimo ao seu público, além de cooperarem nos empreendimentos coletivos organizados pelo Setor de Documentação Técnica e Patentes, ao qual recorrem quando seus recursos não são suficientes para satifazer a esta ou aquela requisição.

Sob a orientação e assistência do Setor de Documentação Técnica, formam, juntamente com os recém-instalados Setores de Documentação dos Serviços de Pessoal e de Organização e Gerência Administrativa, o embrionário sistema de documentação, a que já nos referimos anteriormente.

A distribuição geográfica de nossas Bibliotecas é a seguinte: uma em Belém, quatro em Salvador e proximidades, três no Estado da Guanabara, duas em Duque de Caxias (Estado do Rio), uma em São Paulo e uma em Pôrto Alegre. Mais uma se acha em constituição na Guanabara, junto aos cursos de pós-graduação da Emprêsa. Duas dessas Bibliotecas acham-se subordinadas, tanto técnica como administrativamente, ao órgão central de documentação; as demais, bem como os Setores de Documentação, vinculam-se apenas tècnicamente a êle.

As Bibliotecas da PETROBRÁS são, em regra, de pequeno porte e várias delas apresentam deficiências em seus meios humanos e materiais, típicas de uma fase inicial de instalação. Não obstante, a dedicação e a consciência profissional dos bibliotecários responsáveis têm permitido suprir essas falhas e o serviço desenvolvido pode ser caracterizado como dos mais meritórios.

Os setores de documentação mencionados encontram-se ainda em fase de instalação e o seu objetivo geral é prover os serviços imediatos e especificos de que carecem os órgãos em que se situam. 


\section{CONCLUSOES}

A função documentária na PETROBRÁS está apenas iniciada. Muitos são os requisitos que lhe impõem, tanto em qualidade como em quantidade, o crescimento e a multiplicação das frentes de trabalho da Emprêsa, espalhadas pràticamente por todo o território nacional. A própria técnica documentária, em acelerada transformação, sobretudo no que respeita aos processos de mecanização, também exige de nossos serviços um esfôrço permanente de atualização e renovação.

Tendo em vista que os necessários refinamentos nos métodos e processos adotados requerem, para sua plena realização, a existência preliminar de uma infra-estrutura convenientemente montada, a atenção do Setor de Documentação Técnica e Patentes está no presente voltada para os seguintes aspectos básicos do sistema:

- implantação da compra centralizada de publicações e, por via de conseqüência, da aquisição planificada e dos processos técnicos centralizados;

- melhoramento dos meios e condições oferecidos às Bibliotecas das Unidades de operação da Emprêsa;

- treinamento adequado do pessoal cometido em atividades documentárias.

O simples enunciado dessas medidas de capital importância faz sentir o muito que ainda há por realizar em nossos serviços, a prazo relativamente curto.

Animam-nos, contudo, a boa aceitação que as iniciativas em prática vêm obtendo, bem como a convicção de que, em nossa Emprêsa, o campo é dos mais férteis e propícios para a renovação de métodos e de atitudes que o progresso cientifico-tecnológico requer em escala crescente na sêde de informação especializada. 